\title{
Intelligent Product based on Mobile Agent to Accelerate the New Product Development Process
}

\author{
Abdelhak Boulaalam, El Habib Nfaoui and Omar EI Beqqali \\ Department of Computer Science, Sidi Mohamed Ben AbdEllah University, \\ Faculty of Sciences Dhar El Mahraz, LIIAN laboratory Fez, Morocco
}

Received 2012-12-24, Revised 2013-04-24; Accepted 2013-07-17

\begin{abstract}
To improve the ever-increasing demands products that are customized, all business activities performed along the product life cycle must be coordinated and efficiently managed along the extended enterprise. For this, enterprise had wanted to retain control over the whole product lifecycle especially when the product is in use/repair/recycling (End of Life phase). Although there have been many previous research works about product lifecycle management in the Beginning of Life (BOL) and Middle of Life (MOL) phases, few addressed the End of Life (EOL) phase, in particular. In this study, based on Auto-ID combined with mobile multi-agent system technologies, we will try to improve innovation: (a) by minimize the lunch phase, (b) and the involvement of the customer in product lifecycle (voice of customer).
\end{abstract}

Keywords: Product Life Cycle Management (PLM), EOL, Innovation, Intelligent Product, PEID, Mobile Agent

\section{INTRODUCTION}

In the actual globally changing business environment, enterprises are in search of new ways of providing additional value to customers and gain a competitive over their competitors. Enterprises are focusing on global management of the whole product lifecycles because nowadays worldwide economic conditions demand they make process changes to stay competitive. These change characteristics are reflected in Fig. 1.

The combination between biological and industrial product lifecycle is shown in Fig. 1. This figure is adapted from (Ranasinghe et al., 2011). Past initiatives intended only at product cost, quality, or time-to-market are no longer sufficient to achieve market advantage. The focus today is on innovation (Kiritsis, 2011; Framling et al., 2012; Cardillo et al., 2011; Meyer and Marion, 2012; Xu et al., 2012). In all these research, to improve innovation throughout companies, the focus is on the intelligent product paradigm that it aims to close the product lifecycle between the end of life and the beginning of life.

Corresponding Author: Abdelhak Boulaalam, Department of Computer Science, Sidi Mohamed Ben AbdEllah University, Faculty of Sciences Dhar El Mahraz, LIIAN laboratory Fez, Morocco
There are many projects found in the literature that aims to respond the following points: close the lifecycle, define the intelligent product, improve innovation and involvement of the customers. Since there many research interests to address the information gap through attempts to gather, analyze and share product related data across extended enterprise. Growth in this area of research has accelerated especially by the maturity and the sharp reduction in the cost curve technologies such as Product Embedded Device Identification (PEID). The potency of importance in this field is also demonstrated by research projects such as (Anke et al., 2010) and commercial activities (BOEING, 2012) aimed at using AI (Automatic Identification) for collecting product related data and developing systems to manage and use data gathered throughout lifecycle.

In this research we combine with two technologies, multi agents system especially the mobile agent and the PEIDs, to provide more interactivity between all PLM actors and to add the new level of intelligence such as decision making and integrating the end of life phase. For this, we focus on the tree main ideas: 


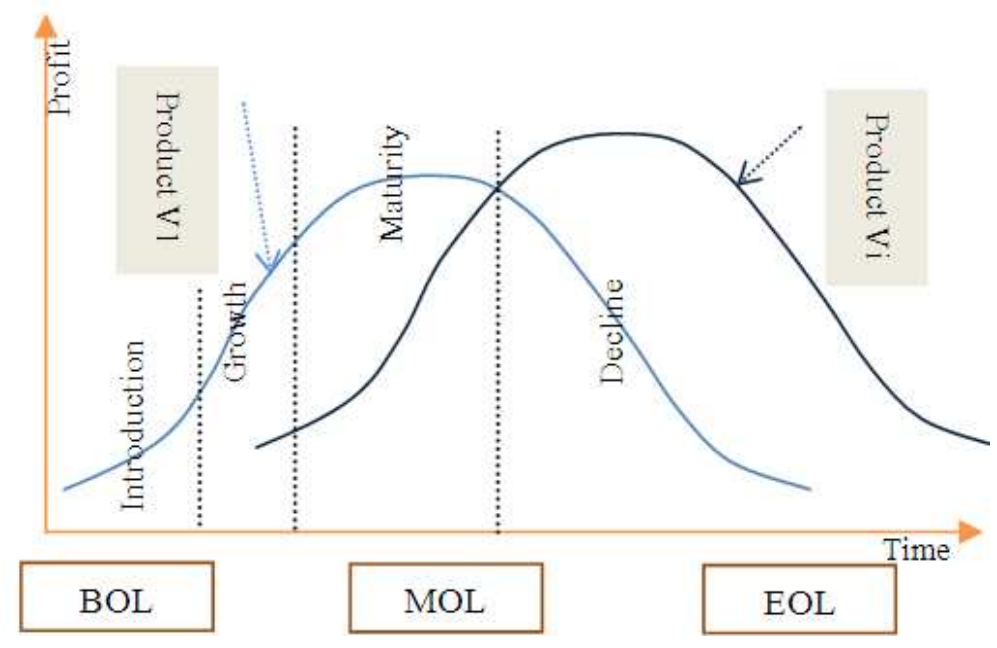

Fig. 1. Combination biological/industrial product life cycle (PLC)

- Creativity because it is the key of innovation

- Agility because productivity is also the speed (time to market), adaptation of organizations to the quickly change of the environment

- Cooperation because the gains lie in the way of combining different activities together, even beyond the walls of each company

\section{REVIEWS OF RELATED STUDIES}

In section 2, we give an overview of related works and the technologies behind our proposed architecture. First we start with the PLM and closed-loop PLM paradigms, next we give some research based intelligent product, then we discuss the MAS and PEID technologies applied in PLM domain, finally we introduce our proposition based on the previous concepts.

\subsection{PLM and Cosed-Loop PLM}

Product Lifecycle Management (PLM) is a concept with multiple interpretations. The must common is about management the data generated in the whole product lifecycle. This concept appeared in the late 1990s moving outside the engineering aspects of a product and providing a shared platform for creation, organization and dissemination of product-related knowledge across the extended enterprise.

CIMdata (2013) defines PLM in four important points:

- A strategic business approach that support the collaborative creation, management, dissemination and use of product definition information
- Supporting the extended enterprise

- Spanning from concept to end of life of a product or plant

- Integrating people, processes, business systems and information

In others terms, CIMdata develops the concept of PLM as knowledge management by gather, storage, processing and usage of product associated knowledge during the life of a product. there many research in the rationale PLM strategies for more and more ability to make better end-of-life decisions and improve detection of deficiencies or failures in the design or manufacturing process (Stark, 2011; Parlikad and McFarlane, 2004), they identified the need to develop a comprehensive platform capable of closing the product information lops from manufacture to its eventual end. Other important definition of the PLM given by (Saaksvuori and Immonen, 2008) that consider PLM system a collaborative backbone allowing people throughout extended enterprises to work together more effectively.

Ranasinghe et al. (2011) characterize the life of a product into three distinct phases as shown in Fig. 2: Beginning, middle and end of life.

- (BOL) refers to the time of activities that take place before an asset begins its useable life

- (MOL) refers to the time of activities

- (EOL) refers to the time of activities involving recycling and disposal 


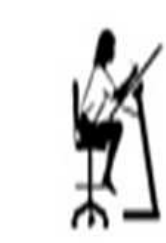

Designers

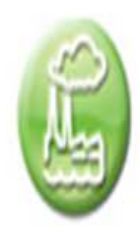

Manufacturing parties
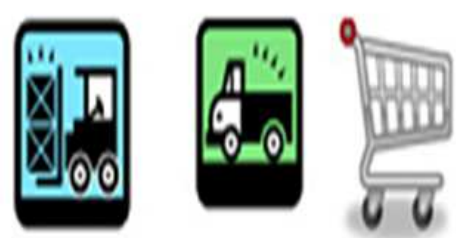

Distributors Dealers

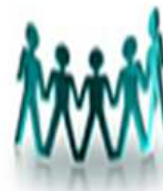

Users

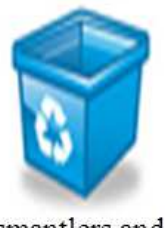

Dismantlers and recyclers

\section{Beginning of life}

Fig. 2. Actors involved in the various stages of a product's life cycle (Ranasinghe et al., 2011)

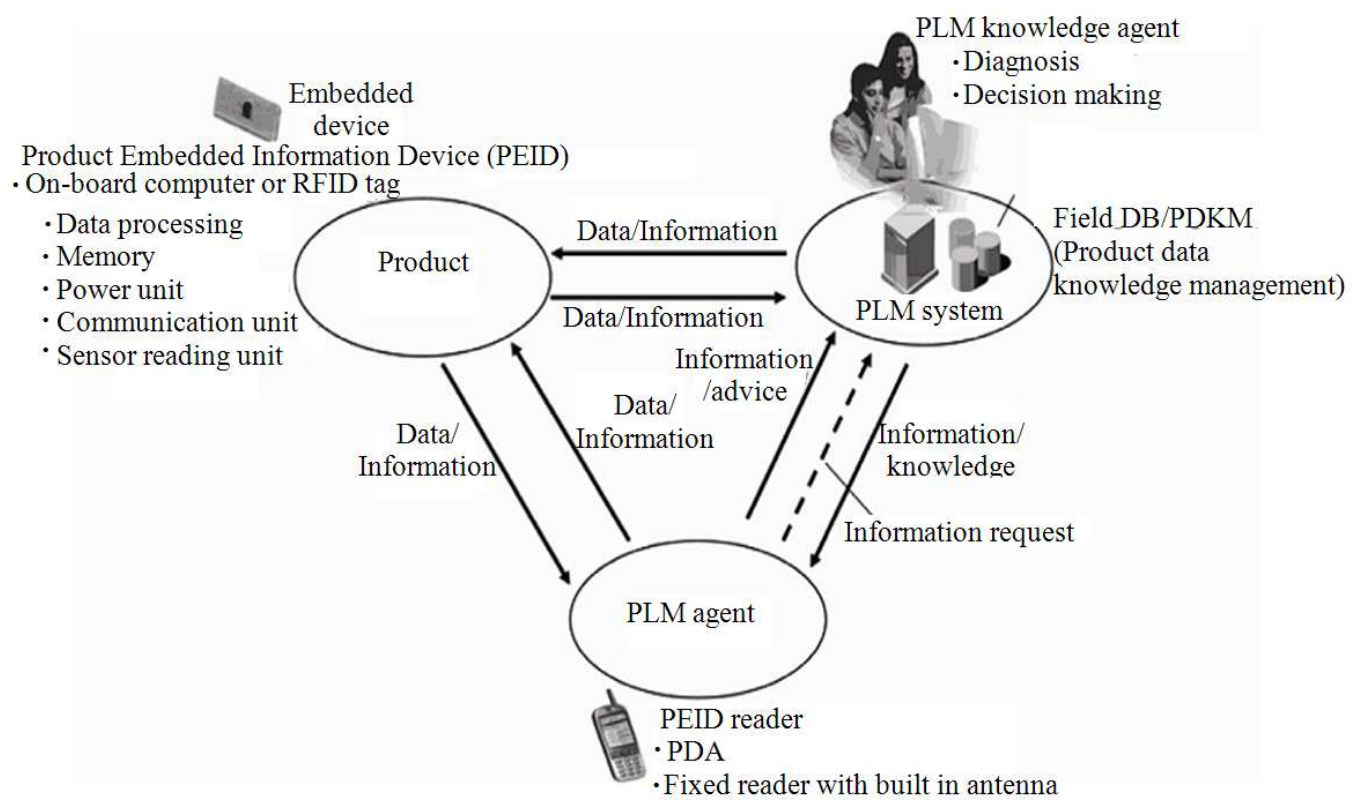

Fig. 3. The closed-loop product lifecycle management concept

Closed-Loop PLM Kiritsis (2011) attempts to extend PLM also to the usage, refurbishing, disposal and other lifecycle phases that product instances go through. The focus is in the end of lifecycle. This proposed strategy is based on the emerging technologies, such as RFID, small size sensors and sensor networks or, more generally, Product Embedded Information Devices (PEID), a new generation of products called intelligent products are appear. The closed-loop PLM concept shown in Fig. 2 illustrates the technologies to be explored and developed (Kiritsis et al., 2008).

\subsection{Intelligent Product}

In the literature, the Intelligent Products have many facets, section 1.2 is mainly focused on the concept behind Intelligent Products, the technical foundations and the achievable goals for the Intelligent Product concept will be presented as a starting point for developing the architecture that assure the closed-loop product lifecycle.

Intelligent Products paradigms in (Framling et al., 2012) have the capabilities to communicate between themselves and with other actors. For this, Intelligent Products link the Auto-ID technology to the agent paradigm and Artificial Intelligence. 
Abdelhak Boulaalam et al. / Journal of Computer Science 9 (7): 856-865, 2013

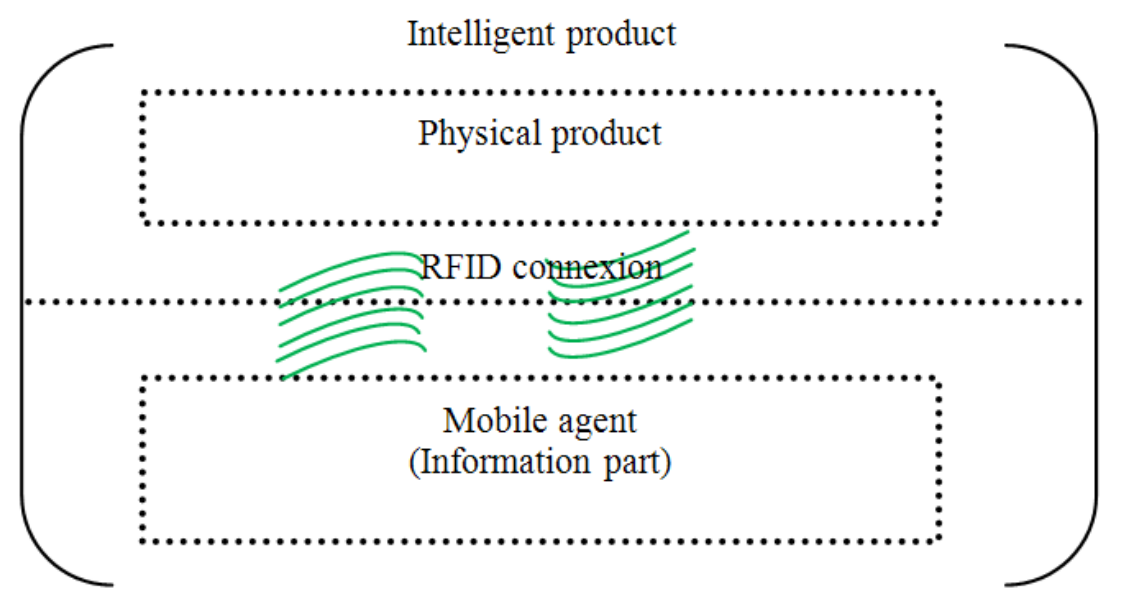

Fig. 4. Intelligent product

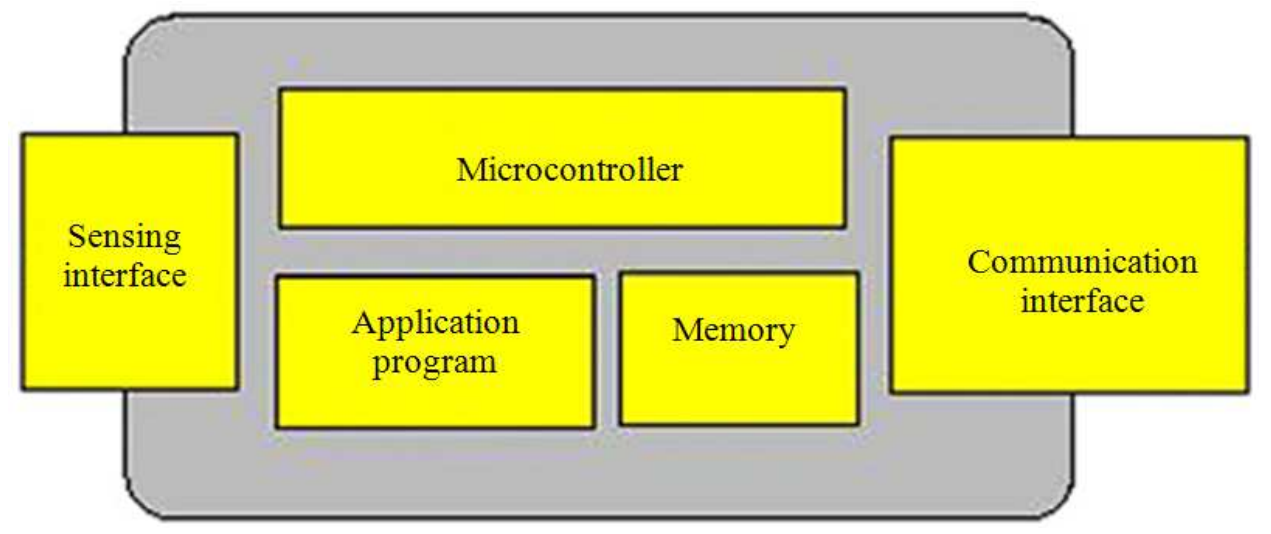

Fig. 5. Intelligent data unit

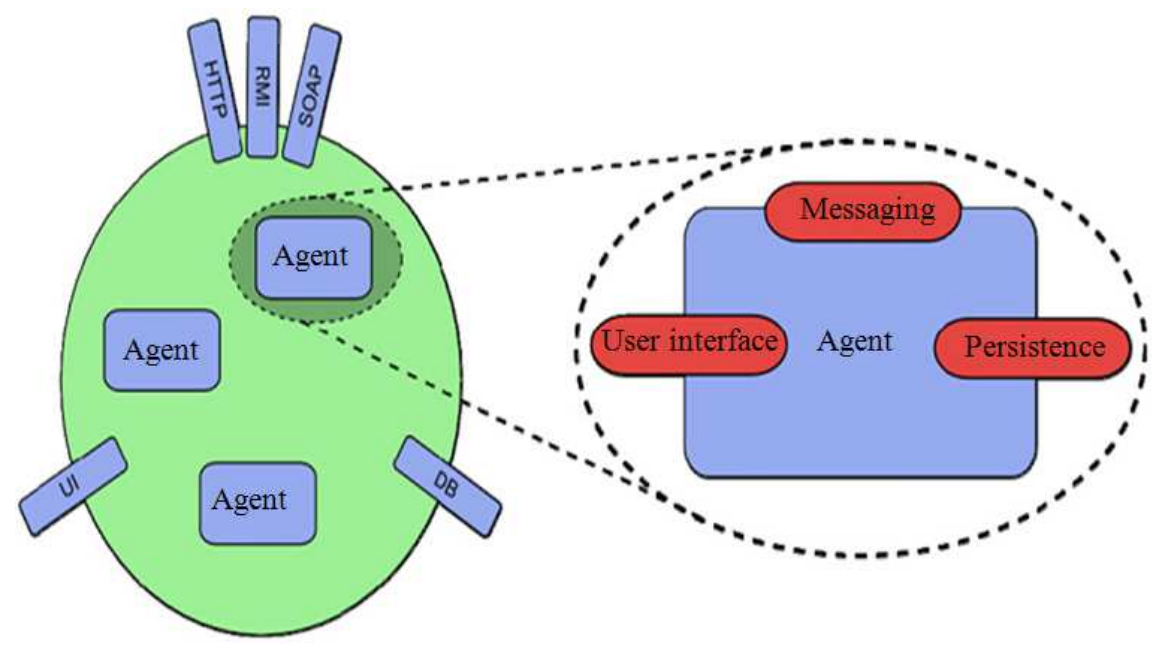

Fig. 6. DIALOG node and agent 
McFarlane et al. (2003), defines five fundamentals proprieties for Intelligent Product:

- Possesses a unique identification

- Is capable of communicating effectively with its environment

- Can retain or store data about itself

- Deploys a language to display its features, production requirements

- Is capable of participating in or making decisions relevant to its own destiny

A product with level 1 product intelligence covers point 1 to 3 , a product with level 2 product intelligence covers all points and is called decision oriented (Wong et al., 2002). This intelligent product classification is based on a separation between the actual product (physical product) and its informationbased counterpart. For this, in PLM context the use of PEID technology is mandatory.

The fundamental idea behind an Intelligent Product according to (Karkkainen et al., 2003) is the inside-out control of the supply chain deliverables and of products during their lifecycle. For inside-out control of products, the products should have:

- Unique identification code

- Links to information sources about the product across organizational borders

- $\quad$ Even pro-actively

In all this definitions the important is focused on intelligent aspect, for this the classification is given in (McFarlane et al., 2003). This classification on intelligent products is divided on two categories, the first level of Intelligence of Intelligent Products (Information handling, Problem notification, Decision making); this three levels respond to the why question. The second classification aims to respond on the HOW question, in other terms the location of intelligence (Intelligence through network, Intelligence at object, intelligent item, intelligent container).

Although various definitions of intelligent products have been proposed, we introduce a new definition of the notion of Intelligent Product based on mobile agent and inspired by what happens in nature with us as human beings and the way we develop intelligence and knowledge. The intelligent product concept illustrated in Fig. 4. In this model, each product is equipped with a PEID such as RFID tag. This is a novel introduced definition of Intelligent Products, which adds the new level of intelligence by using the mobile agent paradigm.

\subsection{Technologies Enabling Intelligent Product}

The concept of intelligent product is formulated (Yang et al., 2009). In this model, each product is equipped with an Intelligent Data Unit. An Intelligent Data Unit is a hardware device that consists of sensors, a controller, memory and data communication interface (Fig. 5).

Auto-ID technologies have been used in the ELIMA (Bodenhoefer et al., 2004) and PROMISE projects. In these projects, the aim is to use auto-ID technology to gather dynamic data about product in automatic manner (Fig. 3).

The idea of Intelligent Products is to seamlessly connect the products (physical world) with their information counterpart in information systems e.g. through a product agent as proposed in (Framling et al., 2003).

\subsection{Multi-Agent Systems}

Various projects applied the multi-agent system paradigm to solve different problems in product lifecycle management (simulation, intelligent product, extended enterprise). Agent technology has already been considered as an important approach for developing industrial distributed systems (Jennings et al., 1995; Jennings and Wooldridge, 1998).

An information system called the Dialog platform (Huvio et al., 2002) that uses ID@URI was initially developed for tracking products through a supply chain. A product identification and information linking concept labeled ID@URI was proposed at Helsinki University of Technology ( $\mathrm{Su}, 2008$; $\mathrm{Su}$ and $\mathrm{Wu}$, 2011). DIALOG system is an open source solution developed at the Helsinki University of Technology. DIALOG is a natural implementation platform for the PROMISE (Framling et al., 2012). The ID@URI concept and the related DIALOG agent make it possible to query and update product information about tangible things over the internet throughout the product lifecycle. As shown in Fig. 6, The DIALOG node contains a simple and configurable mapping mechanism that defines what messages go to which agent(s) and what sender to use for which messages. The proprieties such as protocol, message passing mechanism, security, are implemented by Agents. For this we can say that DIALOG is a "generic" software.

Few of projects founded applied the mobile agent, these entire projects use the stationary agent and even if 
this paradigm is used it's not in the product data management domain (e.g., e-Health, e-Commerce). For the e-Health, based on Aglets Software Development Kit (ASDK), a mobile Multi-Agent based, Distributed Information Platform (MADIP) for wide-area e-health monitoring are proposed to support the intensive and distributed nature of wide-area (e.g., national or metropolitan) monitoring environment $(\mathrm{Su}$ and $\mathrm{Wu}$, 2011). The same project is developed by using the JADE (Java Agent DEvelopment Framework) platform (Xu and Bernard, 2010).

\section{OUR APPROACH}

In the PLM context with the more and more development of technologies, the companies must control his know-how by integrating the product end of life phase. As shown in Fig. 7, the product lifecycle is composed of three phase: begging of life, middle of life and end of life. We focus on the end of life phase in this study. According to (Ranasinghe et al., 2011) end of life phase refers to the time of activities involving recycling and disposal of the asset after it has finished its use phase of the lifecycle. Furthermore, in (Kiritsis, 2011) the EOL phase characterized by diverse scenarios (reuse of the product with refurbishing, reuse of components with disassembly and refurbishing, material reclamation without disassembly, material reclamation with disassembly and, finally, disposal with or without incineration).

In our study we extend the boundaries of the EOL phase, we add the phase of use in this phase. The aim of this extension is the involvement of final customers. Now by using our vision of Intelligent Product, the proposed architecture can improve innovation by optimizing the lunch phase and introduce the new product generation before the end of the ex-product version (Fig. 7).

The mobile agents used in our architecture can join and leave the environment without intervention by a system administrator. The AgentProduct and the physical product have the same ID and with the advent of PEID the AgentProduct is installed on the repair garage, recycling enterprise and embedded on physical product and servers. The overall proposed architecture is depicted in Fig. 8.

A major challenge in the extended enterprise is how to access the information that is not stored only locally or at only one server but is distributed in two or more places. This is also the key technological challenge in implementing the proposed architecture.
By using the intelligent product, the information collected on the product end of life phase can help the designer/manufacturer to improve the design and manufacturing of the products versions and can be readily personalized to meet current and future customer demands.

To satisfy these requirements, a proposed architecture based on PEIDs and mobile multi-agent architecture that is developed on JADE allows MAs to work on behalf of customer, to collect distributed users' knowledge data and to spontaneously inform the use gaps situations to associated PLM actors.

The components of Mobile Agent model used in our research are illustrated in Fig. 9.

The complete architecture is shown in Fig. 11. This architecture is based on Agent's software that can be mobile in the case of the extended enterprise. Five primary architectural features discriminate the proposed architecture: (1) AgentProduct, (2) AgentService, (3) AgentCustomer, (4) AgentImpact and (5) AgentKnowledge. Figure $\mathbf{1 0}$ shows the mobile agent generic implementation level.

In the literatures, knowledge has various dimensions (Norris et al., 2003; Xu et al., 2012). In our proposed architecture we aim to present a global view of product lifecycle by integrating the end of life. For this, the knowledge management in this phase is important. We describes below the scenario for creating the knowledge based on the End of Life phase. We categorize the knowledge (1) by the sources (self or collective), (2) the mode (tacit or explicit). Table 1 summarizes some activities and types for knowledge created within the innovation process (non-exhaustive list).

Knowledge and innovation are two closely interconnected and mutually dependent concepts. Generally, the cumulative information/knowledge of a enterprise leads to its innovations. Furthermore, the explicit and tacit knowledge's (in end of life phase) is inseparable and mutually constituted: (a) the first one (the explicit information/knowledge) is returned by the customer by an interactive participation; for this, we suppose that the product should offer some services such as the detailed operations/uses for new product. The customer could be informed that some components are need to be replaced otherwise the product will have many failures. The direct involvement of the customer provides them access to the suitable information and provides useful information to the manufacturer. (b) The second category is the tacit information/knowledge. 


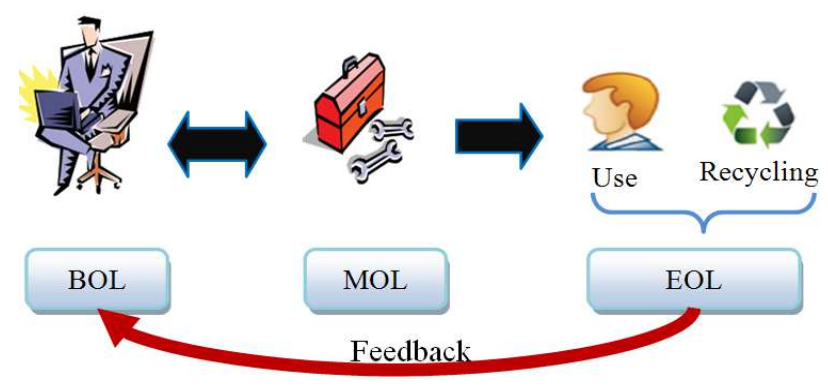

Fig. 7. Architecture overview

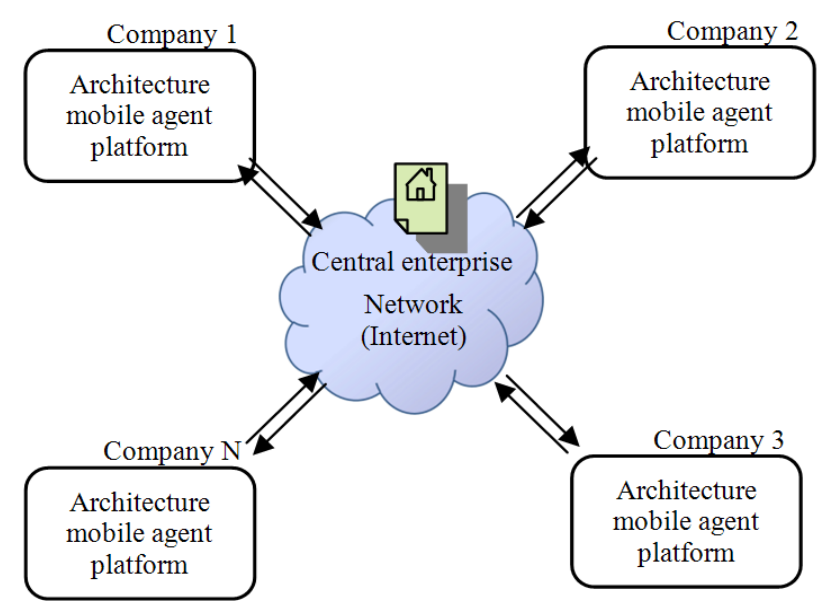

Fig. 8. The overall framework of proposed architecture

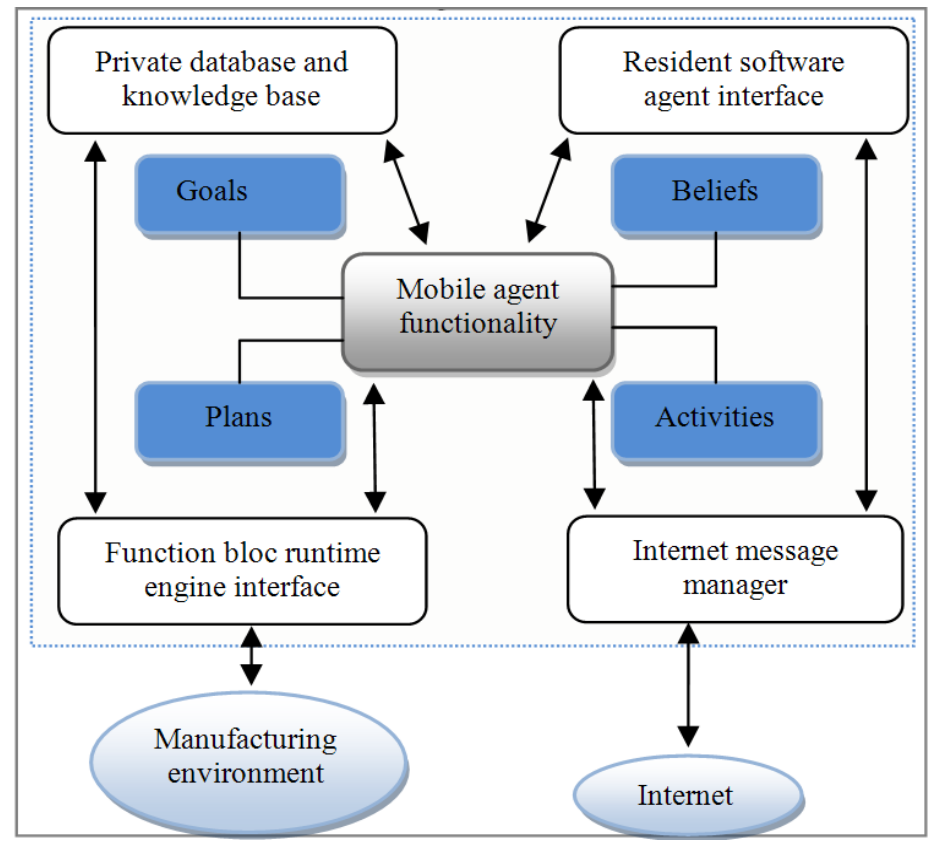

Fig. 9. Mobile agent functionalities 
Abdelhak Boulaalam et al. / Journal of Computer Science 9 (7): 856-865, 2013

\begin{tabular}{|l|}
\hline \multicolumn{1}{|c|}{$\begin{array}{c}\text { " Agent } \\
\text { AgentProduct }\end{array}$} \\
\hline \multicolumn{1}{|c|}{ Attribute } \\
-ID \\
-Name \\
-URLSender: String \\
-URLReceiver: String \\
- homeLocation: Location \\
- currentLocation: Location \\
- previousLocat ion: Location \\
\hline \multicolumn{1}{c|}{ Operations } \\
+clone () \\
+onArrival () \\
+run () \\
+onDeparture () \\
+ge tMyInfo (): AgentDescriptor \\
+ge tCurrentLocation (): Location \\
+migrate (.Location) \\
+send (:Object, :Event)
\end{tabular}

Fig. 10. Example of a class diagram (implementation level)

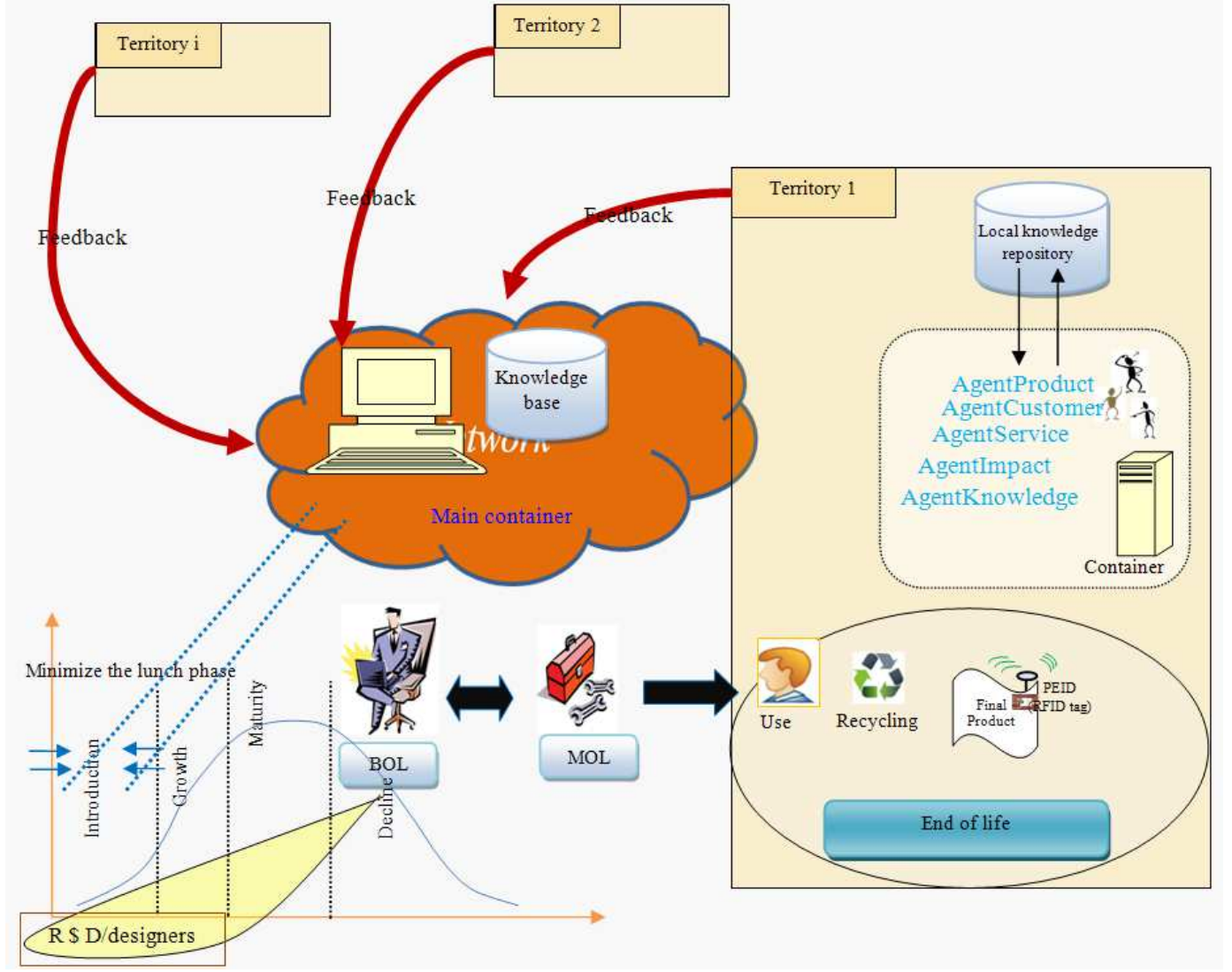

Fig. 11. Our proposed architecture 
Table 1. Activities and types for knowledge created within the innovation process

\begin{tabular}{ll}
\hline Activity & Knowledge type \\
\hline User insight & Tacit and explicit \\
Market invesigation & Explicit \\
Idea and Concept generation & Tacit and explicit \\
Product requirements & Explicit \\
Engennering and Design & Explicit \\
Merketing and Lunch & Tacit and explicit \\
Sales & Tacit and explicit \\
Custommer & Tacit and explicit \\
Product (Intelligent Product) & Tacit \\
\hline
\end{tabular}

Based on the RFID technologies, the detailed information about the product such as the use of product, the environment effects information and the product failure details can be automatically collected. After this, the Agent Product based on Agent Customer, Agent Impact and Agent Knowledge feed the local knowledge repository.

\section{CONCLUSION}

In this study, we provided a new approach focused on the concept of product as a key element (Product in the heart of PLM): the product implicitly embeds the information about itself. For this, it is necessary to add a new dimension to the PLM system in which information flow is horizontally and vertically closed. Starting from the emerging technologies such as product embedded device identification and mobile agent; we proposed an architecture that close the loop product lifecycle management by integrating the end of life phase. For this, we extended the EOL to the use phase. In other terms, this widening aim to implicate the final users in PLM process (involvement of customer). Although this involvement we aim to minimize the lunch phase based on the 'Intelligent Product' feedback: tacit and explicit. Furthermore, in the product use phase, to gather product life cycle data during this phase, the PEID such as RFID has been introduced. Moreover, necessary software components (product information counterpart) and their relations have been addressed: The mobile agent architecture to satisfy the new requirement of extended enterprise. In addition, to streamline several products life cycle operations based on the proposed architecture, the general scenario for creating the knowledge based on the End of Life phase have been introduced.

\section{REFERENCES}

Bodenhoefer, K., A. Schneider, T. Cock, A. Brooks and G. Sands et al., 2004. Environmental life cycle information management and acquisition: First experiences and results from field trials. Proceedings of the Conference on Electronics Goes Green 2004+, Sept. 6-8, Berlin, Germany.

Anke, J., B. Wolf, G. Hackenbroich, H.H. Do and M. Neugebauer et al., 2010. PROMISE: Product lifecycle management and information tracking using smart embedded systems. IGI Global.

BOEING, 2012. Integrated services GoldCare, The Advantages of a Lifecycle Solution from the Airplane OEM.

Cardillo, A., G. Cascini, F. Frillici and F. Rotini, 2011. Computer-aided embodiment design through the hybridization of mono objective optimizations for efficient innovation process. Comput. Indus., 62: 384-397. DOI: 10.1016/j.compind.2010.12.008

CIMdata, 2013. Product Lifecycle Management (PLM) Definition. CIMdata, Inc.

Framling, K., J. Holmstrom, J. Loukkola, J. Nyman and A. Kaustell, 2012. Sustainable PLM through intelligent products. Eng. Appli. Artif. Intell., 26: 789-799. DOI: 10.1016/j.engappai.2012.08.012

Framling, K., J. Holmstrom, T. Ala-Risku and M. Karkkainen, 2003. Product agents for handling information about physical objects. CiteSeerX.

Huvio, E., J. Gronvall and K. Framling, 2002. Tracking and tracing parcels using a distributed computing approach. Proceedings of the 14th Annual Conference for Nordic Researchers in Logistics (RL' 02), Trondheim, Norway, pp: 29-43.

Jennings, N.R. and M. Wooldridge, 1998. Applications of intelligent agents. CiteSeerX.

Jennings, N.R., J.M. Corera and I. Laresgoiti, 1995. Developing industrial multi-agent systems. Proceedings of the 1 st International Conference on Multiagent Systems, (ICMS' 95), AAAI, pp: 423430.

Karkkainen, M., J. Holmstrom, K. Framling and K. Artto, 2003. Intelligent products-a step towards a more effective project delivery chain. Comput. Indus., 50: 141-151. DOI: 10.1016/S01663615(02)00116-1

Kiritsis, D., 2011. Closed-loop PLM for intelligent products in the era of the Internet of things. Comput. Aided Design, 43: 479-501. DOI: $10.1016 /$ j.cad.2010.03.002 
Kiritsis, D., V.K. Nguyen and J. Stark, 2008. How closed-loop PLM improves Knowledge Management over the complete product lifecycle and enables the factory of the future. Int. J. Product Lifecycle Manage., 3: 54-77. DOI: 10.1504/IJPLM.2008.01997

McFarlane, D., S. Sarma, J.L. Chirn, C.Y. Wong and K. Ashton, 2003. Auto id systems and intelligent manufacturing control. Eng. Appli. Artifi Intell., 16: 365-376. DOI: 10.1016/S0952-1976(03)00077-0

Meyer, M.H. and T.J. Marion, 2012. Preserving the integrity of knowledge and information in R\&D. Bus. Horiz., 56: 51-61. 10.1016/j.bushor.2012.09.003

Norris, D.M., J. Mason, R. Robson, P. Lefrere and G. Collier, 2003. A revolution in knowledge sharing. Educ. Rev., 38: 14-26.

Parlikad, A.K. and D. McFarlane, 2004. Investigating the role of product information in end-of-life decision making. Proceedings 11th IFAC Symposium on Information Control Problems in Manufacturing, (SICPM' 04), San Salvador, Brazil.

Ranasinghe, D.C., M. Harrison, K. Fraamling and D. McFarlane, 2011. Enabling through life productinstance management: Solutions and challenges. J. Network Comput. Appli., 34: 1015-1031. DOI: 10.1016/j.jnca.2010.04.019

Saaksvuori, A. and A. Immonen, 2008. Product Lifecycle Management. 3rd Edn., Springer, Berlin, ISBN-10: 3540781722, pp: 253.
Stark, J., 2011. Decision Engineering: Product Lifecycle Management. 2nd Edn., Springer, London, ISBN10: 0857295462, pp: 561.

Su, C.J. and C.Y. Wu, 2011. JADE implemented mobile multi-agent based, distributed information platform for pervasive health care monitoring. Applied Soft Comput., 11: 315-325. DOI: 10.1016/j.asoc.2009.11.022

Su, C.J., 2008. Mobile Multi-Agent based, Distributed Information Platform (MADIP) for wide-area ehealth monitoring. Comput. Indus., 59: 55-68. DOI: 10.1016/j.compind.2007.06.001

Wong, C.Y., D. McFarlane, A.A. Zaharudin and V. Agarwal, 2002. The intelligent product driven supply chain. Proceedings of the IEEE International Conference on Systems, Man and Cybernetics, Oct. 6-9, IEEE Xplore Press. DOI: 10.1109/ICSMC.2002.1173319

Xu, J., R. Houssin, A. Bernard and E. Caillaud, 2012. Systemic modeling of knowledge for innovation in design. CIRP J. Manufact. Sci. Technol., 6: 1-12. DOI: 10.1016/j.cirpj.2012.09.001

$\mathrm{Xu}, \mathrm{Y}$. and A. Bernard, 2010. Measurement of enterprise knowledge by state characterization. Expert Syst., 27: 374-387. DOI: 10.1111/j.14680394.2010.00554.x

Yang, X., P. Moore and S.K. Chong, 2009. Intelligent products: From lifecycle data acquisition to enabling product-related services. Comput. Indus., 60: 184194. DOI: 10.1016/j.compind.2008.12.009 